\title{
Predicting preload responsiveness using simultaneous recordings of inferior and superior vena cavae diameters
}

\author{
Hélène Charbonneau ${ }^{1,2,6^{*}}$, Béatrice Riu ${ }^{1,6}$, Matthieu Faron ${ }^{3}$, Arnaud Mari ${ }^{1,6}$, Matt M Kurrek ${ }^{4}$, Jean Ruiz ${ }^{1,6}$, \\ Thomas Geeraerts ${ }^{1,2}$, Olivier Fourcade ${ }^{1,2}$, Michèle Genestal ${ }^{1,6}$ and Stein Silva ${ }^{1,5,6}$
}

\begin{abstract}
Introduction: Echocardiographic indices based on respiratory variations of superior and inferior vena cavae diameters ( $\triangle S V C$ and $\Delta I V C$, respectively) have been proposed as predictors of fluid responsiveness in mechanically ventilated patients, but they have never been compared simultaneously in the same patient sample. The aim of this study was to compare the predictive value of these echocardiographic indices when concomitantly recorded in mechanically ventilated septic patients.

Methods: Septic shock patients requiring hemodynamic monitoring were prospectively enrolled over a 1-year period in a mixed medical surgical ICU of a university teaching hospital (Toulouse, France). All patients were mechanically ventilated. Predictive indices were obtained by transesophageal and transthoracic echocardiography and were calculated as follows: (Dmax - Dmin)/Dmax for $\triangle S V C$ and (Dmax - Dmin)/Dmin for $\Delta I V C$, where Dmax and Dmin are the maximal and minimal diameters of SVC and IVC. Measurements were performed at baseline and after a $7-\mathrm{ml} / \mathrm{kg}$ volume expansion using a plasma expander. Patients were separated into responders (increase in cardiac index $\geq 15 \%$ ) and nonresponders (increase in cardiac index $<15 \%$ ).
\end{abstract}

Results: Among 44 included patients, 26 (59\%) patients were responders (R). $\Delta$ SVC was significantly more accurate than $\triangle I V C$ in predicting fluid responsiveness. The areas under the receiver operating characteristic curves for $\triangle S V C$ and $\Delta \mathrm{IVC}$ regarding assessment of fluid responsiveness were significantly different ( 0.74 ( $95 \%$ confidence interval $(\mathrm{Cl}): 0.59$ to 0.88$)$ and $0.43(95 \% \mathrm{Cl}: 0.25$ to 0.61$)$, respectively $(P=0.012)$ ). No significant correlation between $\Delta$ SVC and $\Delta \mathrm{IVC}$ was found $(r=0.005, P=0.98)$. The best threshold values for discriminating $\mathrm{R}$ from NR was $29 \%$ for $\Delta \mathrm{SVC}$, with $54 \%$ sensitivity and $89 \%$ specificity, and $21 \%$ for $\Delta I V C$, with $38 \%$ sensitivity and $61 \%$ specificity.

Conclusions: $\triangle S V C$ was better than $\triangle I V C$ in predicting fluid responsiveness in our cohort. It is worth noting that the sensitivity and specificity values of $\Delta S V C$ and $\Delta V C$ for predicting fluid responsiveness were lower than those reported in the literature, highlighting the limits of using these indices in a heterogeneous sample of medical and surgical septic patients.

\section{Introduction}

In patients who present in septic shock, circulatory failure is often the result of hypovolemia, which must be corrected [1]. Volume expansion improves prognosis in this scenario, whereas inappropriate use of vasoconstrictors

\footnotetext{
* Correspondence: charbonneau.h@chu-toulouse.fr

'Département d'Anesthésie Réanimation, CHU Purpan, Université Toulouse 3

Paul Sabatier, Place du Dr Baylac, Toulouse Cedex 9 F-31059, France

${ }^{6}$ Réanimation Polyvalente et Médicine Hyperbare, CHU Purpan, Université

Toulouse 3 Paul Sabatier, Place du Dr Baylac,

Toulouse Cedex 9 F-31059, France

Full list of author information is available at the end of the article
}

can lead to harmful tissue hypoperfusion [2]. However, volume expansion may prove ineffective or even deleterious through worsening of preexisting heart failure or by degrading gas exchanges and compromising oxygen delivery in ventilated patients [3]. It is therefore essential to have reliable bedside tools to predict the efficacy of volume expansion.

Nowadays, the concept of predicting preload responsiveness rather than the traditional assessment of preload responsiveness has been widely proposed as an attractive alternative [4]. Minimal or noninvasive techniques such as transthoracic and transesophageal echocardiography (TTE

\section{Biomed Central}


and TEE, respectively) have gained wide acceptance and are routinely performed by intensivists to evaluate and monitor patients' bedside hemodynamics $[5,6]$. Interestingly, both (noninvasive) TTE and (minimally invasive) TEE allow the echocardiographic examination of the superior and inferior vena cavae diameters and permit assessment of respiratory changes (respiratory variations of the superior vena cava $(\triangle \mathrm{SVC})$ and inferior vena cava $(\Delta \mathrm{IVC}))$. These cyclic changes have been proposed to reflect venous return and to serve as useful predictors of fluid responsiveness in septic patients [7-9]. Nevertheless, it is quite difficult to compare the accuracy of $\triangle S V C$ and $\Delta I V C$, because the clinical studies that have been used to validate each parameter are not comparable in terms of patient population, fluid regimen or criteria used to define a positive response to a fluid challenge [7-9]. Physiologically, the superior and inferior vena cavae are exposed to significantly different pressures, which could explain the reported discrepancies between the predictive values of both parameters [7-9]. In fact, only $20 \%$ of the airway pressure is transmitted to the abdomen [10], and the relationship between venous transmural pressure and venous size is curvilinear [11]. One could thus expect that the increase in downstream pressure induced by mechanical insufflation may cause different diameter changes in the two vena cavae systems during mechanical ventilation. The $\triangle \mathrm{SVC}$ and $\triangle \mathrm{IVC}$ appear to predict fluid responsiveness equally well [7-9], even though they are exposed to different physiological mechanisms. These anatomic and physiologic differences may lead one to assume that $\triangle \mathrm{SVC}$ is better than $\triangle I V C$ in predicting fluid responsiveness. To compare these two predictors, we prospectively studied simultaneous $\triangle \mathrm{SVC}$ and $\triangle \mathrm{IVC}$ recordings in a sample of mechanically ventilated septic patients in a mixed medical and surgical ICU.

\section{Material and methods Patients}

This prospective study was conducted in the ICU of a university hospital (Hôpital Purpan, Toulouse, France). The study was reviewed and approved by the Institutional Review Board (Comité de Protection des Personnes Hospices Civils de Limoges, France, approval CPP10-008a/2010A00616-33). Written informed consent was obtained from each patient's next of kin.

Inclusion criteria were mechanically ventilated patients in septic shock (as defined by the Surviving Sepsis Campaign [1]) who required a rapid volume challenge $(7 \mathrm{ml} / \mathrm{kg}$ of $6 \%$ hydroxyethylstarch for 15 minutes) as directed by the attending physician. The physician's decision was based on the presence of clinical signs of acute circulatory failure (low blood pressure or urine output, tachycardia, mottling) and/or biological signs of organ dysfunction (renal or hepatic dysfunction, lactic acidosis), as well as on the absence of contraindication to a fluid challenge (lifethreatening hypoxemia, echocardiographic evidence of right ventricular failure). Excluded were patients with spontaneous respiratory effort and/or cardiac arrhythmias, as well as those in whom an echocardiographic examination could not be performed (that is, contraindication to TEE [12] or inability to perform TTE $(n=4,8 \%))$.

\section{Measurements}

For each patient, echocardiographic assessments were performed double-blinded simultaneously by two experienced physicians (level 3 echocardiography training) [5] using a Doppler echocardiography device (EnVisor ultrasound system; Philips, Suresnes, France) equipped with a phased array transthoracic probe $(3.5 \mathrm{MHz})$ and a multiplane transesophageal probe $(5 \mathrm{MHz})$. Synchronization of the measurements with the different times of the ventilatory cycle was made possible by displaying the airway pressure curve on the screen of the ultrasound system (Echo Bridge; MAQUET, Rastatt, Germany).

The IVC was examined subcostally in the longitudinal view with the transthoracic probe. Its diameter was measured using the M-mode strictly perpendicular to the vessel and immediately above the juncture with the hepatic vein. Maximal and minimal IVC diameters (Dmax ${ }_{I V C}$ and Dmin $_{\text {IVC }}$, respectively) were measured over a single ventilatory cycle. The $\triangle \mathrm{IVC}$ or the distensibility index of IVC, which reflects the increase of its diameter during mechanical insufflation, was calculated as $\left(\operatorname{Dmax}_{\mathrm{IVC}}-\mathrm{Dmin}_{\mathrm{IVC}}\right)$ / $\mathrm{Dmin}_{\mathrm{IVC}}$ and expressed as a percentage [8]. A $\triangle \mathrm{IVC} \geq 18 \%$ has previously been shown to have the best accuracy for predicting fluid responsiveness [8], and this threshold value was tested in our patients. In addition, we tested another previously published index based on the same measurements $\left.\left.\left(\operatorname{Dmax}_{\mathrm{IVC}}-\mathrm{Dmin}_{\mathrm{IVC}}\right) /\left(\mathrm{Dmax}_{\mathrm{IVC}}+\mathrm{Dmin}_{\mathrm{IVC}}\right) / 2\right)=\Delta \mathrm{IVC}_{2}\right)$, where $\Delta \mathrm{IVC}_{2} \geq 12 \%$ was the best threshold value for predicting fluid responsiveness [9].

The SVC was examined from a long-axis view with a transesophageal probe using the two-dimensional view to locate the M-mode beam across its maximal diameter, as previously described [7]. The SVC diameters ( Dmax $_{\mathrm{SVC}}$ and $\mathrm{Dmin}_{\mathrm{SVC}}$ ) were measured over a single respiratory cycle, and the $\triangle \mathrm{SVC}$ or the collapsibility index of SVC was calculated as $\left(\operatorname{Dmax}_{\mathrm{SVC}}-\mathrm{Dmin}_{\mathrm{SVC}}\right) / \mathrm{Dmax}_{\mathrm{SVC}}$ and expressed as a percentage. As a $\triangle \mathrm{SVC}>36 \%$ has been previously shown to have good accuracy for predicting fluid responsiveness [7], this threshold value was chosen for testing in our patients.

The left ventricular (LV) stroke volume was measured by using a Doppler technique with a transesophageal probe. The pulse Doppler aortic flow velocity-time integral (AoVTI) was determined at the level of the aortic annulus using a transgastric $120^{\circ}$ view and the aortic valve area (SAo) at the level of the aortic annulus. AoVTI was 
measured only with TEE. The stroke volume was then calculated by multiplying AoVTI by Sao, and the cardiac index $(\mathrm{CI})$ was determined by dividing the product of stroke volume and heart rate by the patient's body surface area, as described and validated in previous studies [13]. Changes in CI before (T0) and after fluid challenge (T1) or $\Delta \mathrm{CI}$, were expressed as percentages. We calculated CI by using only TEE data [13].

Additionally, LV systolic function was measured before and after fluid challenge by calculating the LV fractional area change (LVFAC) as previously described [14]. A LVFAC $<40 \%$ was considered as a LV dysfunction.

Measurements of Dmax ${ }_{S V C}$, Dmax ${ }_{\text {IVC }}$ and AoVTI were performed in triplicate over three consecutive respiratory cycles. The results are expressed as the mean of these three measurements. The mean interobserver and intraobserver variabilities in the measurement of $\operatorname{Dmax}_{\mathrm{SVC}}$, Dmax $_{\text {IVC }}$ and AoVTI were $8 \pm 7 \%$ and $5 \pm 6 \%, 9 \pm 9 \%$ and $6 \pm 8 \%$, and $8 \pm 6 \%$ and $5 \pm 4 \%$, respectively.

\section{Study protocol}

All patients were sedated and mechanically ventilated in a volume-controlled mode with a tidal volume of 8 to $10 \mathrm{ml} / \mathrm{kg}$. Two sets of measurements were taken. The first was prior to volume expansion, and the second was immediately after volume expansion. Ventilatory settings as well as dosages of vasopressive drugs were held constant throughout the study. All Doppler echocardiographic measurements were taken offline from videotape recordings.

\section{Statistical analysis}

The effects of volume expansion on hemodynamic parameters were assessed using a nonparametric Wilcoxon rank-sum test. Assuming that a $15 \%$ change in CI was required for clinical significance $[15,16]$, patients were separated into responders $(\mathrm{R})$ and nonresponders (NR) on the basis of a change in cardiac output $\geq 15 \%$ and $<15 \%$, respectively, following the volume challenge. The comparison of hemodynamic parameters prior to volume expansion in $\mathrm{R}$ and NR patients was performed using a nonparametric Mann-Whitney $U$ test.

Receiver operating characteristic (ROC) curves were generated for $\triangle \mathrm{SVC}$ and $\triangle \mathrm{IVC}$, with the discriminating threshold varied for each parameter. The areas under the ROC curves (AUC) for $\triangle$ SVC and $\triangle I V C$ were compared using the nonparametric test published by DeLong et al. [17]. The sensitivity, specificity, positive predictive value and negative predictive value of $\triangle \mathrm{IVC}$ and $\triangle \mathrm{SVC}$ for predicting fluid responsiveness were calculated. The

Table 1 Characteristics of the study patients and comparison between responders and nonresponders at baseline (before fluid challenge) $^{a}$

\begin{tabular}{|c|c|c|c|c|}
\hline Parameters & $\begin{array}{l}\text { All patients } \\
(N=44)\end{array}$ & $\begin{array}{l}\text { Responders } \\
(n=26)\end{array}$ & $\begin{array}{l}\text { Nonresponders } \\
(n=18)\end{array}$ & $P$-value \\
\hline Age, yr & 58.5 (34.8 to 82.6$)$ & 60.4 (36.0 to 84.2) & 51.4 (36.7 to 71.5$)$ & 0.210 \\
\hline BMl & $23.6(17.3$ to 35.2$)$ & 24.3 (17.6 to 40.0$)$ & $22.6(17.7$ to 28.1$)$ & 0.142 \\
\hline Females, $n(\%)$ & $18(40)$ & $13(30)$ & $5(11)$ & 0.245 \\
\hline SAPS ॥ & 67.5 (36.2 to 95.8$)$ & 68.0 (39.6 to 87.3$)$ & 62.5 (34.8 to 97.3$)$ & 0.466 \\
\hline Norepinephrine, $n(\%)$ & $33(75)$ & $20(46)$ & $13(30)$ & 1 \\
\hline Dose of norepinephrine, $\mathrm{mg} / \mathrm{h}$ & 1.7 (0.0 to 5.7$)$ & 1.3 (0.0 to 5.8$)$ & $2.0(0.0$ to 5.6$)$ & 0.91 \\
\hline $\mathrm{V}_{\mathrm{t}}, \mathrm{ml} / \mathrm{kg}$ & $8.2(6.4$ to 11.0$)$ & $8.4(6.5$ to 11.6$)$ & 8.1 (6.1 to 9.7$)$ & 0.315 \\
\hline Respiratory rate, breaths/min & 20 (15 to 26$)$ & 20 (15 to 26$)$ & 21 (16 to 26$)$ & 0.293 \\
\hline PEEP, $\mathrm{cmH}_{2} \mathrm{O}$ & 7 (5 to 12$)$ & $7(5$ to 11$)$ & 7 (5 to 10$)$ & 0.789 \\
\hline Pplat, $\mathrm{cmH}_{2} \mathrm{O}$ & 22 (15 to 27$)$ & 23 (13 to 27$)$ & 21 (16 to 27 ) & 0.801 \\
\hline ARDS, $n(\%)$ & $17(39)$ & $7(27)$ & $10(56)$ & 0.06 \\
\hline $\mathrm{ALI}, n(\%)$ & $12(27)$ & $8(31)$ & $4(22)$ & 0.105 \\
\hline Laparotomy, n (\%) & $10(23)$ & $5(19)$ & $5(28)$ & 0.76 \\
\hline Origin of sepsis, $n(\%)$ & & & & 0.88 \\
\hline Pulmonary & $19(43)$ & $10(39)$ & $9(50)$ & \\
\hline Abdominal or urinary & $17(39)$ & $10(39)$ & $7(39)$ & \\
\hline Skin & $5(11)$ & $4(15)$ & $1(6)$ & \\
\hline Other & $3(7)$ & $2(8)$ & $1(6)$ & \\
\hline
\end{tabular}

${ }^{\mathrm{a}} \mathrm{ALI}$, Acute lung injury $\left(100<\mathrm{PaO}_{2} / \mathrm{FiO}_{2}<300 \mathrm{mmHg}\right) ; \mathrm{ARDS}$, Acute respiratory distress syndrome $\left(\mathrm{PaO}_{2} / \mathrm{FiO}_{2}<200 \mathrm{mmHg}\right) ; \mathrm{BMI} \mathrm{Body}$ mass index; $\mathrm{PaO} / \mathrm{FiO}{ }_{2}$, Ratio of partial pressure of oxygen in arterial blood to fraction of inspired oxygen; Pplat: Plateau pressure; SAPS II: Simplified Acute Physiology Score; $V_{t}$, Tidal volume; PEEP, Positive end-expiratory pressure. Data are expressed as medians with fifth and ninety-fifth percentiles, unless otherwise indicated. 
best cutoff of $\triangle \mathrm{IVC}$ and $\triangle \mathrm{SVC}$ values were defined by the best cutoff of the sensitivity and specificity of each index. Correlations between $\triangle \mathrm{SVC}$ and $\triangle \mathrm{CI}, \triangle \mathrm{IVC}$ and $\triangle \mathrm{CI}$, and $\triangle \mathrm{SVC}$ and $\triangle \mathrm{IVC}$ were assessed using Spearman's $\rho$ coefficient. Linear correlations were tested using the Spearman's rank method. Statistical analysis was performed using $\mathrm{R}$ software version (2.15.1; R Project for Statistical Computing, Vienna, Austria). All $P$-values were two-sided, and a $P$-value of 0.05 was considered significant.

\section{Results and discussion}

Static hemodynamic approach

Forty-four patients with sepsis or septic shock were included over an 11-month period. Twenty-six patients (59\%) were R. Ten patients (22.7\%) died during their ICU stay. Characteristics of the study patients and comparisons between $\mathrm{R}$ and NR at baseline are shown in Table 1. Hemodynamic and echocardiographic data in $\mathrm{R}$ and NR before and after fluid challenge ( $\mathrm{T} 0$ and $\mathrm{T} 1$, respectively) are shown in Table 2. At baseline (T0), CI

Table 2 Hemodynamic characteristics between responders and nonresponders before and after volume expansion ${ }^{a}$

\begin{tabular}{|c|c|c|c|c|}
\hline $\begin{array}{l}\text { Studied } \\
\text { parameters }\end{array}$ & $\begin{array}{l}\text { All patients } \\
(N=44)\end{array}$ & $\begin{array}{l}\text { Responders } \\
(n=26)\end{array}$ & $\begin{array}{l}\text { Nonresponders } \\
(n=18)\end{array}$ & $P$-value \\
\hline \multicolumn{5}{|l|}{ MAP, mmHg } \\
\hline T0 & 71 (53 to 100) & 73 (55 to 100$)$ & 70 (58 to 89 ) & 0.685 \\
\hline $\mathrm{T} 1$ & 78 (58 to 100$)$ & 77 (68 to 102) & 79 (56 to 92) & 0.563 \\
\hline \multicolumn{5}{|l|}{$\mathrm{HR}$, beats/min } \\
\hline T0 & 106 (68 to 141$)$ & 107 (75 to 138$)$ & 101 (61 to 142 ) & 0.99 \\
\hline T1 & 101 (63 to 146$)$ & 102 (70 to 147$)$ & $101(61$ to 142$)$ & 0.738 \\
\hline \multicolumn{5}{|l|}{ CVP, mmHg } \\
\hline T0 & 10 (4 to 17$)$ & 10 (5 to 17$)$ & 8 (3 to 18$)$ & 0.326 \\
\hline T1 & 101 (63 to 146) & 102 (70 to 147$)$ & $101(61$ to 142$)$ & 0.738 \\
\hline \multicolumn{5}{|l|}{ LVFAC, \% } \\
\hline T0 & 46 (21 to 61$)$ & 50 (21 to 59$)$ & 42 (21 to 62 ) & 0.75 \\
\hline $\mathrm{T} 1$ & 47 (23 to 63 ) & 47 (25 to 63 ) & 48 (26 to 61$)$ & 0.861 \\
\hline \multicolumn{5}{|l|}{ AoVTI, cm } \\
\hline T0 & 13.7 (8.2 to 22.8 ) & $13.0(8.3$ to 19.9$)$ & $15.6(10.2$ to 24.1$)$ & 0.06 \\
\hline T1 & 18.0 (12.0 to 23.3$)$ & $18.2(12.0$ to 23.0$)$ & 16.9 (11.2 to 23.5$)$ & 0.527 \\
\hline \multicolumn{5}{|c|}{$\mathrm{Cl}, \mathrm{L} \cdot \min ^{-1} \cdot \mathrm{m}^{-2}$} \\
\hline T0 & 2.3 (1.3 to 3.8 ) & 2.3 (1.3 to 3.4 ) & 2.4 (1.2 to 4.0$)$ & 0.841 \\
\hline T1 & 2.8 (1.5 to 4.3 ) & 3.1 (1.6 to 4.8 ) & 2.5 (1.4 to 3.2 ) & 0.054 \\
\hline \multicolumn{5}{|l|}{$\operatorname{Dmax}_{\mathrm{SVC}}, \mathrm{mm}$} \\
\hline T0 & 13.2 (8.2 to 20.4$)$ & $12.0(8.3$ to 19.8$)$ & $14.0(9.2$ to 22.6$)$ & 0.05 \\
\hline $\mathrm{T} 1$ & 14.6 (8.9 to 21.7$)$ & 13.5 (8.5 to 22.4$)$ & $15.0(10.4$ to 19.1$)$ & 0.568 \\
\hline \multicolumn{5}{|l|}{$\Delta S V C, \%$} \\
\hline TO & 20 (6 to 47) & 31 (7 to 49) & 16 (5 to 30$)$ & 0.01 \\
\hline T1 & 12 (3 to 63 ) & 15 (4 to 68 ) & $6(0$ to 25$)$ & 0.008 \\
\hline \multicolumn{5}{|l|}{ Dmax $_{\mathrm{IVC}}, \mathrm{mm}$} \\
\hline T0 & 19.6 (12.0 to 23.1) & 19.0 (12.0 to 28.9$)$ & 19.9 (11.1 to 24.9$)$ & 0.67 \\
\hline T1 & 21.1 (12.9 to 28.0) & 19.6 (12.1 to 28.1$)$ & $22.2(16.1$ to 25.1$)$ & 0.218 \\
\hline \multicolumn{5}{|l|}{$\Delta \mathrm{IVC}, \%$} \\
\hline T0 & 18 (2 to 55$)$ & 12 (2 to 55$)$ & 20 (3 to 58 ) & 0.453 \\
\hline T1 & 9 (2 to 26$)$ & 10 (0 to 30$)$ & 6 (3 to 25$)$ & 0.47 \\
\hline
\end{tabular}

${ }^{\mathrm{a} A o V T I}$, Pulse Doppler aortic velocity time integral; $\mathrm{Cl}$, Cardiac index; CVP, Central venous pressure; Dmax ${ }_{\mathrm{IVC}}, \mathrm{Maximal}_{\mathrm{I}}$ diameter of inferior vena cava; Dmax ${ }_{\mathrm{SVC}}$ Maximal diameter of superior vena cava; HR, Heart rate; $\triangle \mathrm{IVC}$, Distensibility index of inferior vena cava; LVFAC, Left ventricular fractional area change; MAP, Mean arterial pressure; $\triangle \mathrm{SVC}$, Collapsibility index of superior vena cava; T0, Before volume expansion; T1, After volume expansion; VTI, Velocity time integral. Data are expressed as medians with $95 \%$ confidences intervals. P-value corresponds to the comparison between Responders and Nonresponders at each time point (T0 and T1). Data are expressed as medians with fifth and ninety-fifth percentiles. 
was not significantly different between $\mathrm{R}\left(2.3 \mathrm{~L} \cdot \mathrm{min}^{-1} \cdot \mathrm{m}^{-2}\right.$ (95\% CI: 1.3 to 3.4$)$ ) and NR (2.4 $\mathrm{L} \cdot \mathrm{min}^{-1} \cdot \mathrm{m}^{-2}(95 \% \mathrm{CI}$ : 1.3 to 3.9$))(P=0.841)$. Overall ( $\mathrm{R}$ and $\mathrm{NR})$, heart rate, mean arterial blood pressure and central venous pressure increased significantly after volume expansion $(P<0.005$ for all comparisons).

\section{Predicting fluid responsiveness With superior vena cava dynamic measurements} Individual values of $\triangle \mathrm{SVC}$ according to fluid responsiveness are shown in Figure 1. In our sample, the best cutoff value of $\triangle \mathrm{SVC}$ to predict fluid responsiveness was $29 \%$ with a sensitivity of $54 \%$ (95\% CI: 35 to 73 ) and a specificity of $94 \%$ (95\% CI: 83 to 105). A poor correlation between $\triangle \mathrm{SVC}$ and $\triangle \mathrm{CI}$ was found $(r=0.307, P=0.04)$. A $\triangle \mathrm{SVC}>36 \%$ allowed us to discriminate between $\mathrm{R}$ and NR in our sample with a sensitivity of $42 \%$ (95\% CI: 23 to 61), a specificity of $100 \%$ (95\% CI: 100 to 100 ), a positive predictive value of $100 \%$ (95\% CI: $100-100)$ and a negative predictive value of $55 \%$ ( $95 \%$ CI: 38 to 72 ).

It is worth noting that excluding patients $(n=18$, $40.9 \%)$ with low tidal volume $(<8 \mathrm{ml} / \mathrm{kg})$ and with low heart and respiratory rate $(\mathrm{HR} / \mathrm{RR})$ ratios $(<3.6)$ did not significantly change the diagnostic value (sensitivity of 47\% (95\% CI: 23 to 71), a specificity of 100\% (95\% CI: $100-100)$, a positive predictive value of $100 \%$ (95\% CI: $100-100)$ and a negative predictive value of $50 \%(95 \%$ CI: 27 to 73$)$ ).

\section{With inferior vena cava dynamic measurements}

Individual values of $\triangle \mathrm{IVC}$ according to fluid responsiveness are shown in Figure 2. In our sample, the best cutoff value of $\triangle \mathrm{IVC}$ was $21 \%$ with a sensitivity of $38 \%$ (95\% CI: 19 to 57] and a specificity of 61\% (95\% CI: 38 to 84 ). No correlation between $\triangle \mathrm{IVC}$ and $\triangle \mathrm{CI}$ was observed $(r=-0.178, P=0.26)$. In our sample, $\Delta \mathrm{IVC} \geq 18 \%$ allowed for discrimination between $\mathrm{R}$ and NR with a sensitivity of $42 \%$ (95\% CI: 22 to 62), a specificity of $39 \%$ (95\% CI: 16 to 62), a positive predictive value of $48 \%$ (95\% CI: 27 to 69 ) and a negative predictive value of 33\% (95\% CI: 13 to 53). When patients ventilated with low tidal volume and those with low HR/RR ratios were excluded, the sensitivity was $44 \%$ (95\% CI: 20 to 68 ) (for $\Delta \mathrm{IVC} \geq 18 \%$ ), the specificity was $33 \%$ ( $95 \% \mathrm{CI}: 2$ to 64 ), the positive predictive value was $54 \%$ (95\% CI: 27 to 81 ) and the negative predictive value was $25 \%$ ( $95 \%$ CI: 1 to 50 ). The AUC for $\Delta \mathrm{IVC}_{2}(\triangle \mathrm{IVC}$ as described by Feissel et al. [9]) was similar to the $\Delta \mathrm{IVC}$ as described by Barbier et al. [8] (0.43 (95\% CI: 0.25 to 0.61$)$ ).

\section{Comparison of $\triangle$ SVC and $\triangle I V C$ as predictors of fluid responsiveness}

The AUC for $\triangle \mathrm{SVC}$ and $\triangle \mathrm{IVC}$ regarding assessment of fluid responsiveness showed that $\triangle S V C$ showed better

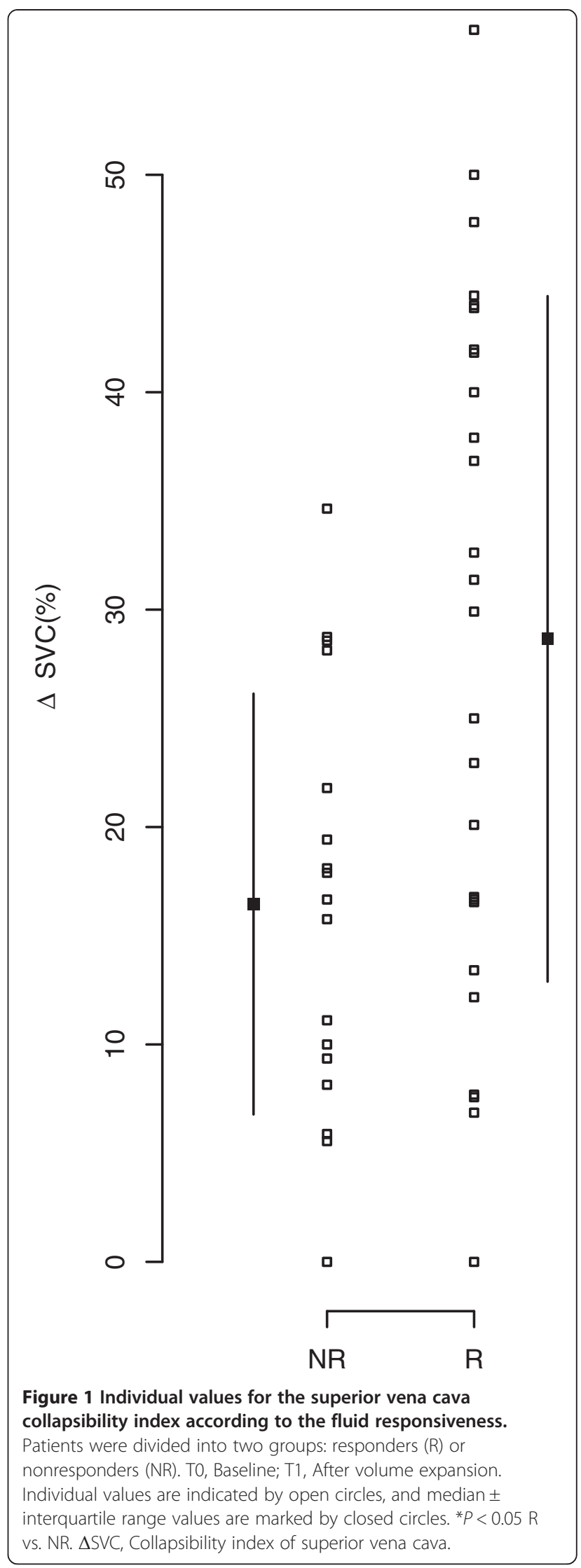


Figure 2 Individual values for the inferior vena cava distensibility index according to the fluid responsiveness. Patients were divided into two groups: responders (R) or nonresponders (NR). T0, Baseline; T1, After volume expansion. Individual values are indicated by open circles, and median \pm interquartile range values are marked by closed circles. ${ }^{*} P<0.05 R$ vs. NR.

accuracy compared to $\triangle \mathrm{IVC}(0.74$ (95\% CI: 0.59 to 0.88$)$ versus 0.43 (95\% CI: 0.25 to 0.61$)(P=0.012)$ (Figure 3$)$. No significant correlation between $\triangle \mathrm{SVC}$ and $\triangle \mathrm{IVC}$ was found $(r=0.005, P=0.98)$. $\triangle \mathrm{SVC}$ and $\triangle \mathrm{IVC}$ were significantly lower after volume expansion $(P<0.001)$, whereas changes for Dmax ${ }_{\mathrm{SVC}}$ and Dmax $\mathrm{IVC}_{\mathrm{IVC}}$ were not significant ( $P=0.16$ and $P=0.06$, respectively). Despite the significant difference between $\mathrm{R}$ and NR, the AUC of $\mathrm{D}_{\operatorname{maxSVC}}$ remained low (0.67 (95\% CI: 0.51 to 0.85$)$ ).

We assessed right ventricular function in all of the cases and detected three cases of right ventricular failure (right/left >0.6). In none of the three cases did we observe a difference in reactivity between IVC and SVC.

Overall, these results are in agreement with our main hypothesis of a dissociation between the ability of these dynamic vena cavae measurements to predict preload responsiveness. The better predictive value of $\triangle \mathrm{SVC}$ could be due to a comparatively greater mechanical insufflationinduced decrease in venous return at the intrathoracic level compared to the intra-abdominal level. The greater impact of intrathoracic pressure variation could be related to (1) a greater increase in right atrial pressure (that is, in the back pressure to venous return) [10], (2) a greater increase of the right ventricular impedance due to the collapse of poorly filled alveolar vessels [18] or (3) the occurrence of a venous waterfall phenomenon between the extrathoracic and intrathoracic vena cavae segments [19]. Because our study was designed to be part of routine clinical practice, we were unable to determine which of the mechanisms described above was predominant. Furthermore, it must be highlighted that both indices were found to be less sensitive and less specific than previously reported. In our study, a $\Delta \mathrm{SVC}>36 \%$ predicted fluid responsiveness with high specificity $(100 \%)$ and high positive predictive value (100\%), but with poor sensitivity (42\%). Several explanations for such discrepancies between the present study and previously published work are possible $[7,20]$. First, the mechanical ventilation settings were not similar. The respiratory rate and PEEP were higher in our study than in the study by Vieillard-Baron et al. [7] (20 breaths/min and 5 to $11 \mathrm{cmH}_{2} \mathrm{O}$ vs. 15 breaths/min and 5 to $7 \mathrm{cmH}_{2} \mathrm{O}$ ). The ability of the SVC to collapse in the thorax is influenced by intrathoracic pressure and volume, and different HR/RR ratios may impact its reliability to predict fluid responsiveness [21]. In our study, one-third of patients had acute respiratory distress syndrome 


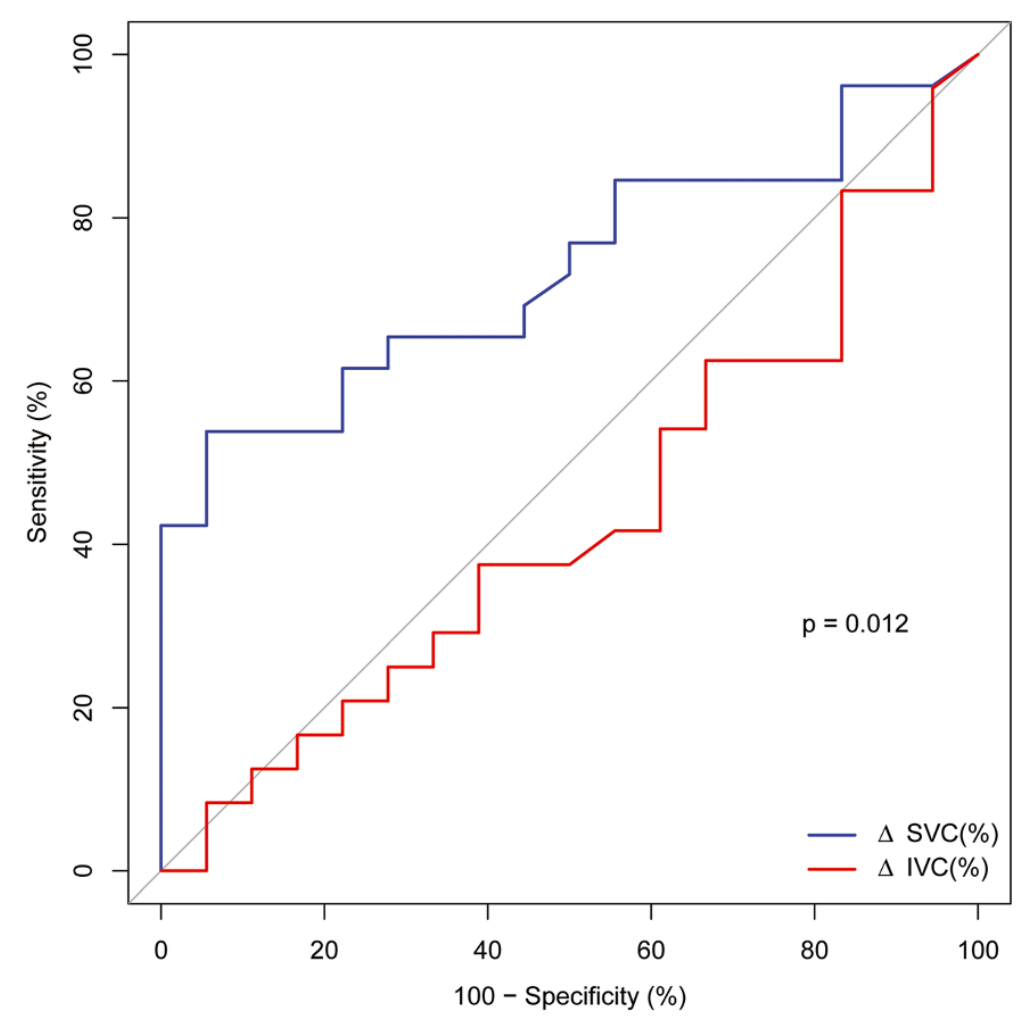

Figure 3 Receiver operating characteristic curves comparing the ability of superior vena cava collapsibility index and inferior vena cava distensibility index to discriminate between responders and nonresponders. The area under the receiver operating characteristic (ROC) curve for the collapsibility index of superior vena cava $(\Delta S V C)(0.74 ; 95 \% \mathrm{Cl}: 0.59$ to 0.88$)$ differed significantly from the area under the ROC curve for the distensibility index of inferior vena cava ( $\Delta \mathrm{IVC})(0.43 ; 95 \% \mathrm{Cl}: 0.25$ to 0.61$)(P=0.012)$.

(ARDS), and $40.9 \%$ were ventilated with low tidal volumes and had HR/RR ratios $<3.6$. The parameters used to assess fluid responsiveness in this patient group have been questioned [22], and the low tidal volumes required in our patients with ARDS and low pulmonary compliance may have impacted the ability of $\triangle \mathrm{SCV}$ to predict fluid responsiveness, indicating the potential limitation of the use of this index in such patients. We mention elsewhere that, in our present study, 26 patients $(60 \%)$ were ventilated with a tidal volume $>8 \mathrm{ml} / \mathrm{kg}$. Although this may seem high by today's standards, it was, at the time of the first patient's inclusion in March 2011, recommended to ventilate only patients with acute lung injury or ARDS with a low tidal volume $(<8 \mathrm{ml} / \mathrm{kg})$ [1]. Second, Vieillard-Baron and colleagues defined $\mathrm{R}$ as an increase $>11 \%$ in $\mathrm{CI}$, whereas we selected $15 \%$ to be consistent with data reported in the current literature $[8,9,15,16,23,24]$; however, the sensitivity remained poor (39\%), even when we used $\Delta \mathrm{CI} \geq 11 \%$. A larger proportion of our cohort received vasopressor support (75\% versus $50 \%)$, and it has been shown that norepinephrine can affect fluid challenge [25].

Our results show that the AUC for $\triangle \mathrm{SVC}$ regarding assessment of fluid responsiveness was low (0.74 (95\% CI: 0.59 to 0.88$)$ ). Contrary to the findings of other investigators, we discovered that, in real-life ICU practice conditions, the AUC of $\triangle \mathrm{IVC}$ seems not to be a reliable predictor of fluid responsiveness and that its TEE counterpart, $\triangle \mathrm{SVC}$, shows a poor fluid responsiveness except for the high variation levels.

Regarding the IVC, in contrast with previous researchers, we found a poorer sensitivity (42\%) and specificity (39\%), despite the fact that we used the same threshold of $\triangle I V C(\geq 18 \%)$ [8]. Several physiological hypotheses should be considered. For instance, because the IVC is mainly intra-abdominal, its ability to distend could be limited by an increase in intra-abdominal pressure, especially in postoperative abdominal surgery patients. In a recent study, the impact of intra-abdominal pressure on IVC diameter was evaluated in mechanically ventilated pigs. The results showed that IVC diameters are affected by intra-abdominal pressure and that fluid responsiveness should not be estimated from retrohepatic IVC diameter in cases of high intra-abdominal pressure [26]. Our results show a weak AUC for $\triangle \mathrm{IVC}(0.43$ (95\% CI: 0.25 to 0.61$)$ ), suggesting that $\triangle I V C$ may not be a consistently reliable predictor of fluid responsiveness.

Our results, as compared to those of previously published studies, suggest that in ARDS patients, a standard 
ventilation strategy, high vasopressor infusion rate and/or abdominal surgery may alter the ability of $\triangle \mathrm{SVC}$ and $\triangle I V C$ to predict fluid responsiveness and that these predictive indices should be investigated extensively and refined before any generalized use can be recommended. Furthermore, the selection of a single cutoff point for making clinical decisions may be too simplistic. A "gray zone" approach applied to the pulse pressure variations for prediction of fluid response in mechanically ventilated patients under general anesthesia was recently suggested by Cannesson et al. [27]. This "gray zone" approach has not been used in our study, because the size of our cohort did not permit such statistical analysis.

\section{Conclusions}

In a heterogeneous sample of mechanically ventilated septic patients in medical and surgical ICUs, $\triangle S V C$ appeared to have better accuracy than $\triangle \mathrm{IVC}$ for predicting fluid responsiveness. A cutoff $>36 \%$ identified $\mathrm{R}$ with high specificity and positive predictive value. However, our results also suggest that the accuracy of both $\triangle \mathrm{SVC}$ and $\triangle I V C$ as predictors of fluid responsiveness is lower than that reported in the literature, thus raising questions about their reliability in patients with ARDS, postoperative abdominal surgery patients or patients treated with high vasopressor infusion rates. In our opinion, a complete evaluation of volume status in septic and mechanically ventilated patients should include both IVC and SVC examinations.

\section{Key messages}

- $\triangle \mathrm{SVC}$ appears to have better accuracy than $\triangle \mathrm{IVC}$ for predicting fluid responsiveness in ventilated septic patients.

- The accuracy of both $\triangle \mathrm{SVC}$ and $\triangle \mathrm{IVC}$ as predictors of fluid responsiveness was lower than data reported in the literature, raising questions about their reliability in patients with ARDS, postoperative abdominal surgery patients or patients treated with high vasopressor infusion rates.

\footnotetext{
Abbreviations

AoVTI: Pulse Doppler aortic velocity time integral; ARDS: Acute respiratory distress syndrome; BMI: Body mass index; Cl: Cardiac index; CVP: Central venous pressure; Dmaxivc: Maximal diameter of inferior vena cava; Dmax $_{\text {Svc: }}$ Maximal diameter of superior vena cava; HR: Heart rate; HR/ RR: Heart rate/respiratory rate; LVFAC: Left ventricular fractional area change; MAP: Mean arterial pressure; NR: Nonresponders to fluid challenge; PEEP: Positive end-expiratory pressure; Pplat: Plateau pressure; R: Responders to fluid challenge; SAPS II: Simplified Acute Physiology Score; $V_{t}$ : Tidal volume; $\Delta \mathrm{IVC}$ : Distensibility index of inferior vena cava; $\triangle$ SVC: Collapsibility index of superior vena cava.
}

\section{Competing interests}

The authors declare that they have no competing interests.

\section{Authors' contributions}

$\mathrm{HC}$ and SS made contributions to the design of the study, the acquisition of data, the analysis and interpretation of data, and the drafting of the manuscript. BR contributed to the design and conception of the study and drafted the manuscript. MF participated in the design of the study, performed the statistical analysis and drafted the manuscript. AM and JR participated in data acquisition, performed the echocardiographic examinations and drafted the manuscript. MK contributed substantially to data interpretation and critically revised the draft manuscript. TG contributed substantially to data interpretation and drafted the manuscript. MG and OF contributed substantially to the conception of the work and critically revised the draft manuscript. All authors read and approved the final manuscript. All authors agree to be accountable for all aspects of the work.

\section{Author details}

'Département d'Anesthésie Réanimation, CHU Purpan, Université Toulouse 3 Paul Sabatier, Place du Dr Baylac, Toulouse Cedex 9 F-31059, France. ${ }^{2}$ EA 4564 "Modélisation de l'agression tissulaire et nociceptive", University Toulouse 3 Paul Sabatier, Toulouse, France. ${ }^{3}$ Department of Biostatistics and Epidemiology, Gustave Roussy, Villejuif, France. ${ }^{4}$ Department of Anesthesia, University of Toronto, Toronto, ON, Canada. ${ }^{5}$ INSERM U825, CHU Purpan, Place du Dr Baylac, Toulouse Cedex 9 F-31059, France. ${ }^{6}$ Réanimation Polyvalente et Médicine Hyperbare, CHU Purpan, Université Toulouse 3 Paul Sabatier, Place du Dr Baylac, Toulouse Cedex 9 F-31059, France.

Received: 18 March 2014 Accepted: 23 July 2014

Published online: 05 September 2014

\section{References}

1. Dellinger RP, Levy MM, Carlet JM, Bion J, Parker MM, Jaeschke R, Reinhart K, Angus DC, Brun-Buisson C, Beale R, Calandra T, Dhainaut JF, Gerlach H, Harvey M, Marini JJ, Marshall J, Ranieri M, Ramsay G, Sevransky J, Thompson BT, Townsend S, Vender JS, Zimmerman JL, Vincent JL: Surviving Sepsis Campaign: international guidelines for management of severe sepsis and septic shock: 2008. Intensive Care Med 2008, 34:17-60. A published erratum appears in. Intensive Care Med 2008, 34:783-785.

2. Weil MH, Nishjima H: Cardiac output in bacterial shock. Am J Med 1978, 64:920-922.

3. Michard F, Biais M: Rational fluid management: dissecting facts from fiction. Br J Anaesth 2012, 108:369-371.

4. Richard C, Warszawski J, Anguel N, Deye N, Combes A, Barnoud D, Boulain T, Lefort Y, Fartoukh M, Baud F, Boyer A, Brochard L, Teboul JL, the French Pulmonary Artery Catheter Study Group: Early use of the pulmonary artery catheter and outcomes in patients with shock and acute respiratory distress syndrome: a randomized controlled trial. JAMA 2003, 290:2713-2720.

5. Mayo PH, Beaulieu Y, Doelken P, Feller-Kopman D, Harrod C, Kaplan A, Oropello J, Vieillard-Baron A, Axler O, Lichtenstein D, Maury E, Slama M, Vignon P: American College of Chest Physicians/La Société de Réanimation de Langue Française statement on competence in critical care ultrasonography. Chest 2009, 135:1050-1060.

6. Expert Round Table on Ultrasound in ICU: International expert statement on training standards for critical care ultrasonography. Intensive Care Med 2011, 37:1077-1083.

7. Vieillard-Baron A, Chergui K, Rabiller A, Peyrouset O, Page B, Beauchet A, Jardin F: Superior vena caval collapsibility as a gauge of volume status in ventilated septic patients. Intensive Care Med 2004, 30:1734-1739.

8. Barbier C, Loubières Y, Schmit C, Hayon J, Ricôme JL, Jardin F, Vieillard-Baron A: Respiratory changes in inferior vena cava diameter are helpful in predicting fluid responsiveness in ventilated septic patients. Intensive Care Med 2004, 30:1740-1746.

9. Feissel M, Michard F, Faller JP, Teboul $J$ : The respiratory variation in inferior vena cava diameter as a guide to fluid therapy. Intensive Care Med 2004, 30:1834-1837.

10. van den Berg PCM, Jansen JRC, Pinsky MR: Effect of positive pressure on venous return in volume-loaded cardiac surgical patients. J Appl Physiol 2002, 92:1223-1231.

11. Amoore JN, Santamore WP: Venous collapse and the respiratory variability in systemic venous return. Cardiovasc Res 1994, 28:472-479.

12. Vignon $P$, Guéret $P$, Chabernaud JM, Lacroix $P$, Maudière $A$, Cassat $C$, Doumeix JJ, Abrieu O, Sénéchal C, Bensaid J: Failure and complications of 
transesophageal echocardiography: 1500 consecutive cases [Article in French]. Arch Mal Coeur Vaiss 1993, 86:849-855.

13. Darmon PL, Hillel Z, Mogtader A, Mindich B, Thys D: Cardiac output by transesophageal echocardiography using continuous-wave Doppler across the aortic valve. Anesthesiology 1994, 80:796-805. discussion 25A.

14. Vieillard-Baron A, Charron C, Chergui K, Peyrouset O, Jardin F: Bedside echocardiographic evaluation of hemodynamics in sepsis: Is a qualitative evaluation sufficient? Intensive Care Med 2006, 32:1547-1552.

15. Michard F, Boussat S, Chemla D, Anguel N, Mercat A, Lecarpentier Y, Richard C, Pinsky MR, Teboul JL: Relation between respiratory changes in arterial pulse pressure and fluid responsiveness in septic patients with acute circulatory failure. Am J Respir Crit Care Med 2000, 162:134-138.

16. Feissel M, Michard F, Mangin I, Ruyer O, Faller JP, Teboul JL: Respiratory changes in aortic blood velocity as an indicator of fluid responsiveness in ventilated patients with septic shock. Chest 2001, 119:867-873.

17. DeLong ER, DeLong DM, Clarke-Pearson DL: Comparing the areas under two or more correlated receiver operating characteristic curves: a nonparametric approach. Biometrics 1988, 44:837-845.

18. Jardin F, Delorme G, Hardy A, Auvert B, Beauchet A, Bourdarias JP. Reevaluation of hemodynamic consequences of positive pressure ventilation: emphasis on cyclic right ventricular afterloading by mechanical lung inflation. Anesthesiology 1990, 72:966-970.

19. Squara P, Dhainaut JF, Schremmer B, Sollet JP, Bleichner G: Decreased paradoxic pulse from increased venous return in severe asthma. Chest 1990, 97:377-383.

20. Vieillard-Baron A, Augarde R, Prin S, Page B, Beauchet A, Jardin F: Influence of superior vena caval zone condition on cyclic changes in right ventricular outflow during respiratory support. Anesthesiology 2001, 95:1083-1088

21. De Backer D, Taccone FS, Holsten R, Ibrahimi F, Vincent J-L: Influence of respiratory rate on stroke volume variation in mechanically ventilated patients. Anesthesiology 2009, 110:1092-1097.

22. Teboul JL, Monnet X: Pulse pressure variation and ARDS. Minerva Anestesiol 2013, 79:398-407.

23. Teboul JL, group d'experts de la SRLF: Recommendations of an SRLF expert group: indicators of volume resuscitation during circulatory failure [Article in French]. Ann Fr Anesth Reanim 2005, 24:568-581.

24. Monnet X, Rienzo M, Osman D, Anguel N, Richard C, Pinsky MR, Teboul J-L: Passive leg raising predicts fluid responsiveness in the critically ill. Crit Care Med 2006, 34:1402-1407.

25. Persichini R, Silva S, Teboul JL, Jozwiak M, Chemla D, Richard C, Monnet X: Effects of norepinephrine on mean systemic pressure and venous return in human septic shock*. Crit Care Med 2012, 40:3146-3153.

26. Bendjelid K, Viale JP, Duperret S, Colling J, Piriou V, Merlani P, Jacques D: Impact of intra-abdominal pressure on retrohepatic vena cava shape and flow in mechanically ventilated pigs. Physiol Meas 2012, 33:615-627.

27. Cannesson M, Le Manach Y, Hofer CK, Goarin JP, Lehot JJ, Vallet B, Tavernier B: Assessing the diagnostic accuracy of pulse pressure variations for the prediction of fluid responsiveness: a "gray zone" approach. Anesthesiology 2011, 115:231-241.

doi:10.1186/s13054-014-0473-5

Cite this article as: Charbonneau et al:: Predicting preload responsiveness using simultaneous recordings of inferior and superior vena cavae diameters. Critical Care 2014 18:473.

\section{Submit your next manuscript to BioMed Central and take full advantage of:}

- Convenient online submission

- Thorough peer review

- No space constraints or color figure charges

- Immediate publication on acceptance

- Inclusion in PubMed, CAS, Scopus and Google Scholar

- Research which is freely available for redistribution

Submit your manuscript at www.biomedcentral.com/submit 